\title{
INTERNAL EXAMINATION EVALUATION SYSTEM
}

\author{
Mr.Malikjan Bagawan \\ Dept. of Computer Science and Engineering \\ KLE Dr. M S Sheshgiri college of Engg and Technology \\ Belagavi, Karnataka, India
}

\begin{abstract}
Internal examination evaluation system is a web based evaluation system. The main goal of this evaluation system is to provide a centralized system which could be beneficial to various colleges or institutes to store the soft copies of student's internal examination papers or answer scripts, and it also provides effective platform to the teaching staff to evaluate the papers or answer scripts online in secured manner. It minimizes the effort, time, and cost taken for manual paper valuation.
\end{abstract}

Keywords - Internal Examination, valuation system, digital valuation

\section{INTRODUCTION}

Internal examination evaluation system is a web based application, the goal of this project is to develop one centralized system for colleges to store the soft copies of student's internal examination papers or answer sheets and the evaluator can evaluate the paper online in secure manner. Using this system the evaluator can see the soft copy of the internal examination papers, he/she can enter the marks \& can easily generate the result sheet, and the main objective is to minimize the cost, time and working process, reduce manual effort of valuation of internal examination papers and give the best and efficient results.

Internal Paper valuation is very important task in any college, school, university or organization. In India there are the various universities, under these universities there are several colleges and they are running various courses like engineering, medical and other degree courses. Every year nearly the 6 internal test are conducting for every class, after each test the teachers have to carry the answer sheet from centralized location in secure environment, then evaluate them enter marks manually and keep them in same secure environment manually.

This evaluation process where physically answer sheet to be stored at central location in secure environment. Exam paper checker need to visit this centralized location collect papers and evaluate answer sheets of the individual students. If there are hundreds of students are writing internal papers it is an important constraint to carry them manually and also need to maintain the papers securely for longer period of time.

\author{
Prof. Uma Hombal \\ Dept. of Computer Science and Engineering \\ KLE Dr. M S Sheshgiri college of Engg \& Technology \\ Belagavi, Karnataka, India
}

\section{LITERATURE SURVEY}

Today, lot of Institutes or colleges deals with the larger number of internal examination papers or answer scripts and it takes a huge amount of time, effort to evaluate papers manually, and accuracy is also not guaranteed in manual valuation.The Visvesvaraya Technological University (VTU) Belgavi will currently using the digital evaluation system to evaluate the semester final exam papers, similarly the Bangalore University is also introduces the digital valuation system for some undergraduate courses. In the VTU digital valuation system[1] each answer script is given a bar code and scanned by machines. The scanned copies are then uploaded onto the VTU server and each evaluator will log into the username assigned to him and the evaluator can evaluate the papers assigned to them.10 answer scripts will be assigned to evaluator at a time. On the first day, evaluators will need to correct 30 scripts, on second day 40 , and 50 scripts from the third day onwards explained by $\mathrm{H}$ Maheshappa vice chancellor VTU Belagavi[2].

\section{PROBLEM DEFINITION}

Current Internal paper valuations or answer sheet valuations are carried out in a physical manner, that consumes more time, effort and it is difficult to transfer or carry and maintain all students answer scripts. The proposed Internal Examination Evaluation System will provide a platform to stores soft copy all answers scripts and also provide the functionality to evaluate the paper online in secure manner.

\section{EXISTING SYSTEM}

Colleges/Universities are still not providing any platform to evaluate semester internal examination papers. Institutes/colleges evaluate thousands of internal examination papers or answer scripts per semester and the amount of cost and effort is huge in case of manual or physical valuation. Internal examination evaluation system will resolve these problems in effective manner. The internal exam evaluation is physical now, where subject teacher has to carry answer sheet with them or have to do valuation in college only. It is Very 


\section{International Journal of Engineering Applied Sciences and Technology, 2020 \\ Vol. 5, Issue 1, ISSN No. 2455-2143, Pages 679-682 \\ Published Online May 2020 in IJEAST (http://www.ijeast.com)}

much time consuming and it is difficult to maintain the papers for longer period of time.

\section{PROPOSED SYSTEM}

Internal examination evaluation system saves exam papers or answer scripts, students and staff information in database which is clone to cloud, in this system the admin can add/delete students, staff, subject information, upload scanned copy of students answer scripts and assigns the staff for valuation. The authorized staff can see the uploaded answer scripts of students and enter the marks and save it, the total marks are calculated automatically as per the college criteria and report is generated.

\section{SYSTEM DESIGN AND IMPLEMENTATION}

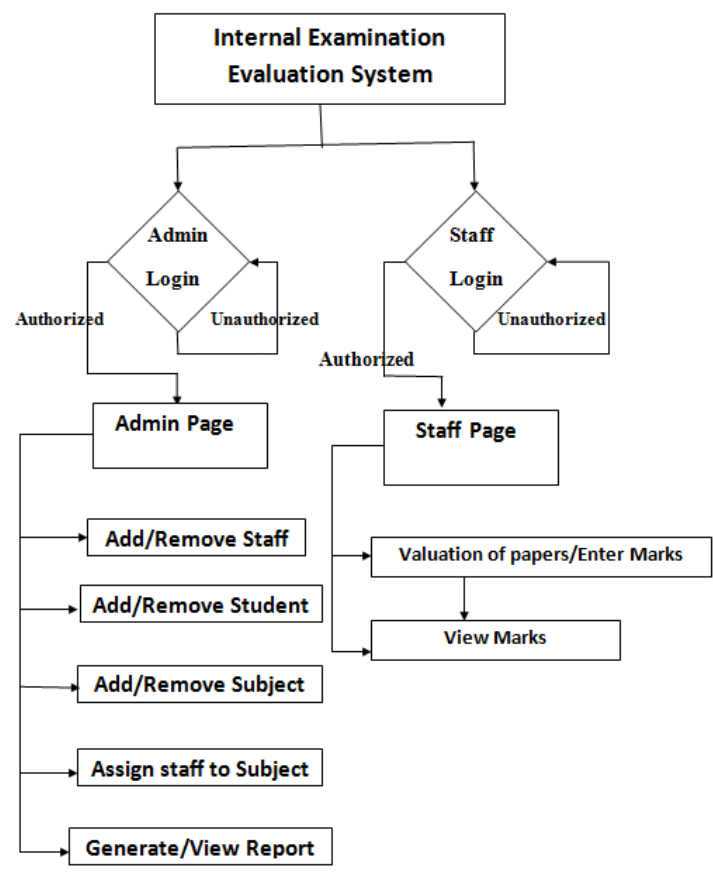

Fig 1. General Diagram

\section{I.Modularization details:}

The Internal Examination Evaluation System includes the following Modules

A. Admin Module:

- Add Subject: Admin can add subject semester wise

- Add staff: Admin can add staff (teacher) for valuation

- Assign subject: Admin can assign subject to respected staff

- $\quad$ Add Student: Admin can add student as per semester

- Upload Answer sheet: Admin can Scan and upload answer sheet of students as per there registration number and subject wise.

- $\quad$ Reports: Admin can generate reports
B. Staff (Teacher) Module:

- Login: staff can login in the system with user id and password.

- Paper valuation: staff can see the scan copy papers assigned to him/her and enter the marks.

- View marks: staff can also view the marks.

To implement this system use JSP, HTML, and Java scripts technologies [3][4][5], which are helps to design the front end of the system and for back end data storage use the SQL server[6].

\section{SYSTEM INTERFACE}

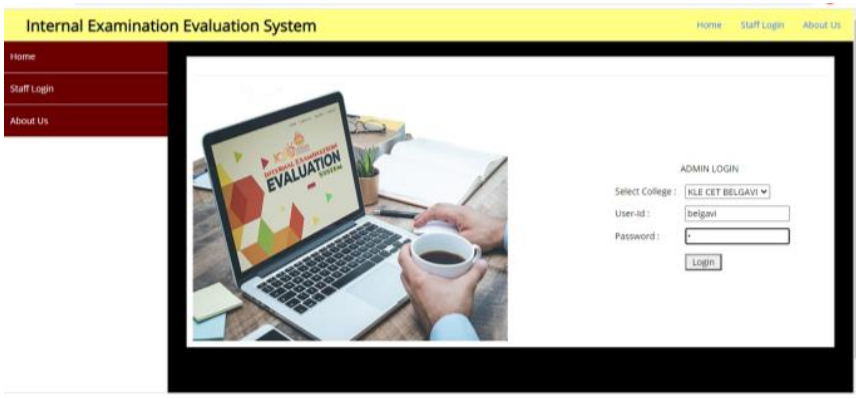

Fig.2 Home Page (includes admin login and staff login)

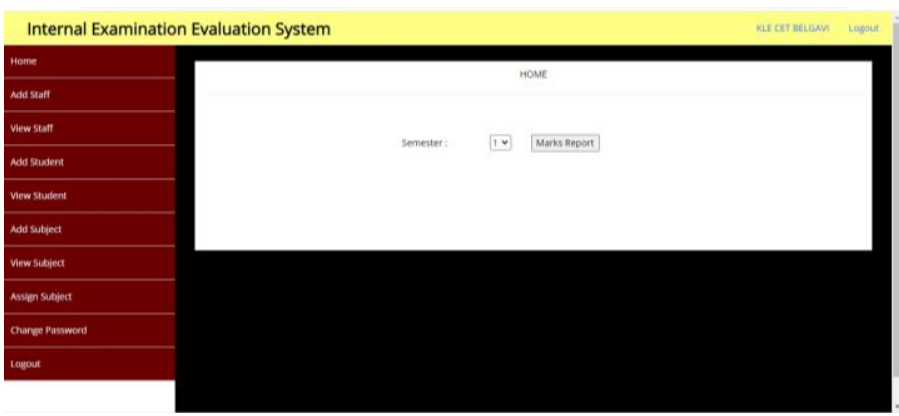

Fig. 3 Admin Page (admin can add/remove staff, student, subjects, upload answers sheets and subject to staff)

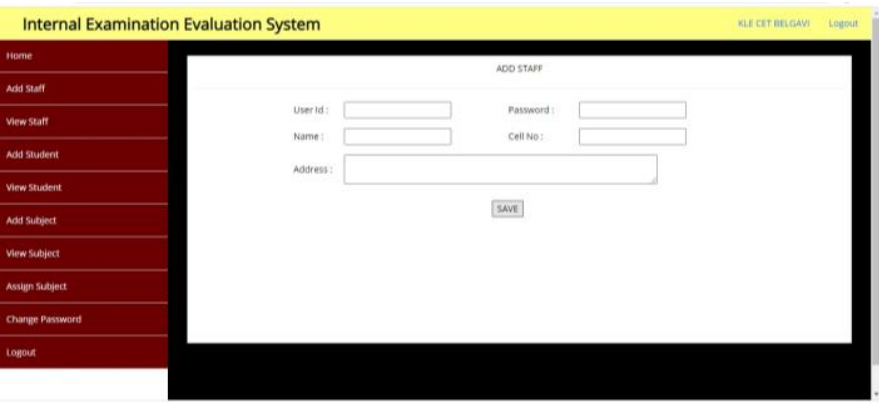

Fig. 4 Add staff 
International Journal of Engineering Applied Sciences and Technology, 2020

Vol. 5, Issue 1, ISSN No. 2455-2143, Pages 679-682

Published Online May 2020 in IJEAST (http://www.ijeast.com)

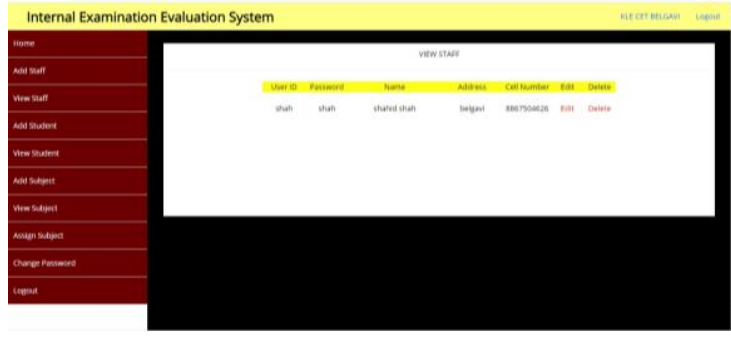

Fig. 5 View staff

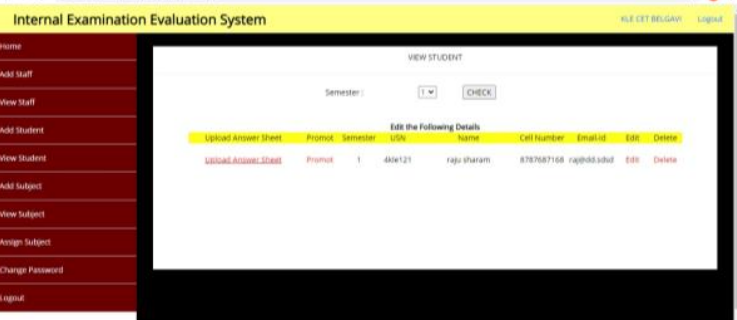

Fig. 6.1 Upload answer sheet

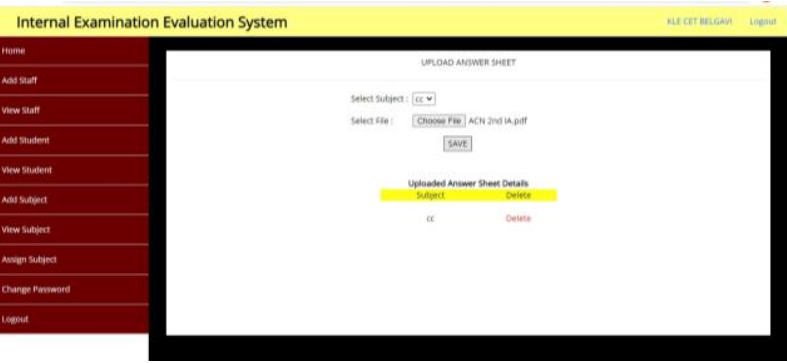

Fig. 6.2 Upload answer sheet

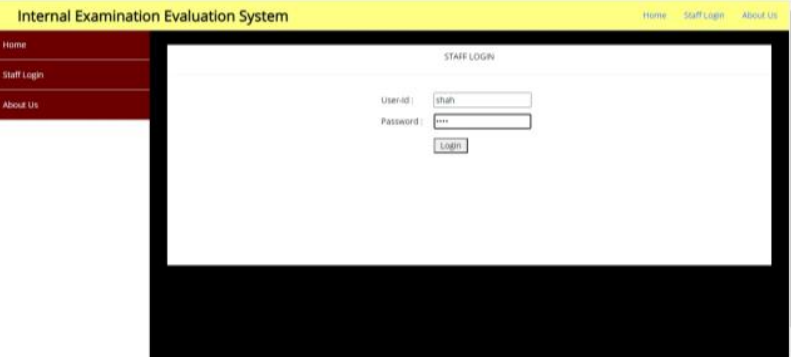

Fig. 7 Staff Login

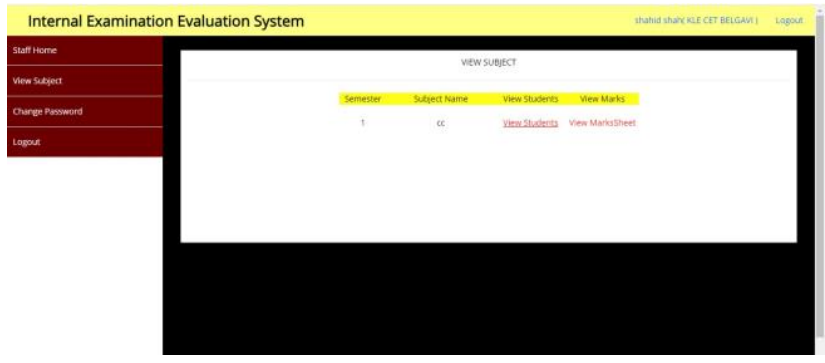

Fig. 8 View Subject (for staff)

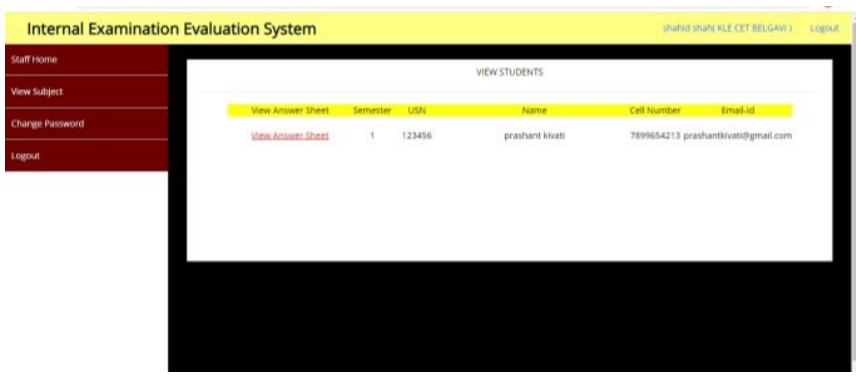

Fig. 9 View Student (for staff)

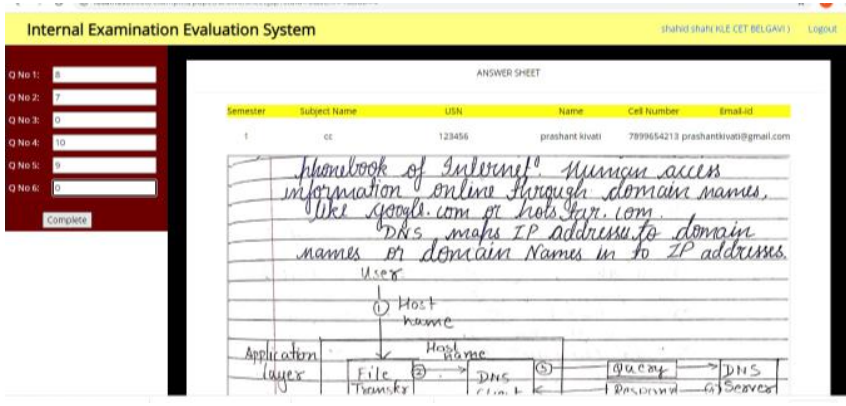

Fig. 10 Paper Valuation \& Marks entry page (for staff)

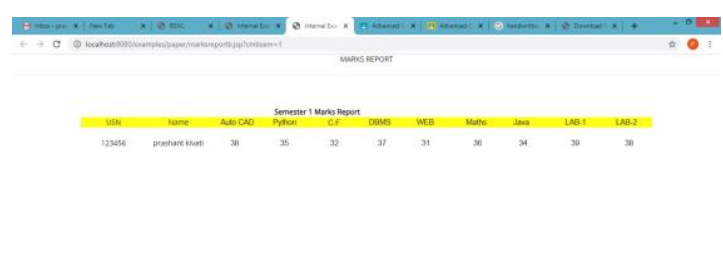

a

Fig. 11 Marks Report 


\section{CONCLUSION}

The proposed internal examination evaluation system can be easily adopted by colleges or institutions in order to make the internal exam paper valuation more effective, secure and more flexible. The system is divided into two main subsystems (staff and administrator) that are designed to give the system maximum benefit by demonstrating carefully each subsystem service. The administrator's functions are clearly identified to be able to add, remove the staff, students, subject information; admin can also upload the answer script, assign to the staff and generate the report. Staff can enter the marks and can see the marks entered. Thus, the proposed system is easy and flexible for future maintenance and development and each subsystem can be handled separately without influence on other system.

\section{REFERENCES}

[1] Muna R. Hameed , Firas. A. Abdullatif "Online Examination System",International Advanced Research Journal in Science, Engineering and Technology ISO 3297:2007 Certified Vol. 4, Issue 3, March 2017.

[2] https://www.deccanherald.com/state/karnataka-hc-ordersrelease-of-payment-to-litigants-854564.html

[3] Advanced Programming for the Java 2 Platform by: Calvin Austin \& Monica Pawlan. Java 2 Complete Reference

[4] https://tomcat.apache.org/download-80.cgi

[5] https://www.w3schools.com

[6] https://support.microsoft.com/en-in/help/956139/actionsthat-are-required-before-you-install-sql-server-2008-on-acomp 